\title{
THE PLASMA LEVELS OF VITAMIN A AFTER THE INGESTION OF STANDARD DOSES: STUDIES IN NORMAL SUBJECTS AND PATIENTS WITH CIRRHOSIS OF THE LIVER ${ }^{1}$
}

\author{
By ELAINE P. RALLI, ELI BAUMAN, AND LESLIE B. ROBERTS \\ (From the Third (New York University) Medical Division of Bellevue Hospital and the De- \\ partment of Medicine, New York University, College of Medicine, New York City)
}

(Received for publication July 10, 1941)

In a previous study it was found that the livers of patients with cirrhosis of the liver contained much less vitamin $A$ than did the livers of normal subjects (1). The concentration of carotene was also lower in the livers of the patients with cirrhosis but was not as strikingly reduced as was the liver vitamin A. More recently, we have observed that the plasma levels of vitamin $A$ and carotene were lower in patients with cirrhosis of the liver than in normal subjects (2). Apparently, the low level of vitamin $A$ in the plasma reflected the diminished amounts of vitamin $A$ in the livers of patients with cirrhosis. This suggested that there might be an appreciable difference in the plasma levels of vitamin A following the administration of a standard dose of vitamin A to normal subjects and to patients with cirrhosis.

Observations were therefore made on a group of normal subjects, on 5 patients with cirrhosis, and on a patient with acute catarrhal jaundice. The patients with cirrhosis gave histories of chronic alcoholism.

\section{PROCEDURE}

The normal group consisted of 12 male adults. Vita$\min A$ was given by mouth in the form of a cod liver oil concentrate. Four of the normal subjects received the equivalent of 20,000 U.S.P. units of vitamin A. This was $1 \mathrm{cc}$. of the cod liver oil concentrate. Eight of the normal subjects were given an amount of the concentrate equivalent to 100,000 U.S.P. units of vitamin $A$ and this dose was also given to the 5 patients with cirrhosis and the patient with acute catarrhal jaundice. Prior to the administration of the vitamin, the range of the plasma levels of vitamin A was established in each subject by repeated daily determinations. Following the oral administration of cod liver oil, the plasma levels of vitamin $A$ and carotene were determined at intervals of $3,6,9$, 12 , and 24 hours. When it was found that, in the normal subjects, no further increase in the level of vitamin A

1 This research was aided by a grant from The Milbank Memorial Foundation. occurred at 9 and 12 hours, the determinations at these intervals were omitted in the normals.

Vitamin A, after extraction from the plasma, was determined in the photoelectric colorimeter, using antimony trichloride. The method, with slight modifications, was similar to that reported by Kimble (3). The carotene concentration was determined in the photoelectric colorimeter by the method described by Stueck et al. (4). In order to calculate the concentration of vitamin $\mathrm{A}$ in the plasma in U.S.P. units, calibration curves were done, using a standard U.S.P. reference oil that contained 1700 U.S.P. units of vitamin A per gram. Calibration curves were also done for beta-carotene with antimony trichloride. To correct for the blue color due to carotene in the extracted plasma, the concentration of carotene in the petroleum ether extract of the plasma was determined and subtracted from the galvanometer reading for the total blue value obtained. The result gave the value for vitamin A.

\section{RESULTS}

The effects of the cod liver oil concentrate on the plasma levels of vitamin $\mathrm{A}$ and carotene are summarized in Table I. Figure 1 shows the individual plasma levels of vitamin $\mathrm{A}$ in the normal subjects receiving 100,000 U.S.P. units of vitamin $A$ and in the 5 patients with cirrhosis of the liver.

Following the administration of 20,000 U.S.P. units of vitamin $A$ to the 4 normal subjects, there was a rise in the plasma level of vitamin $A$, which occurred in 3 cases after 6 hours and in 1 case after 3 hours. The average increase in the plasma level was 84 U.S.P. units. After 12 hours the plasma levels in all 4 cases had returned to about the original fasting levels. During this time there were no changes in the plasma levels of carotene. In fact, the carotene remained quite constant.

The 8 other normal subjects each received 100,000 U.S.P. units of vitamin A. Following this dose there was a much sharper increase in the plasma levels of vitamin A, as is shown in the figure. The peak of this increase was reached 
TABLE I

Effect of large doses of vitamin $A$ in the form of a cod liver oil concentrate on the plasma levels of vitamin $A$ in normal subjects, in patients with cirrhosis of the liver and in a case of acute catarrhal jaundice

\begin{tabular}{|c|c|c|c|c|c|c|c|c|c|c|c|c|c|c|}
\hline \multirow{3}{*}{ Group } & \multirow{3}{*}{$\begin{array}{c}\text { Num- } \\
\text { ber } \\
\text { of cases }\end{array}$} & \multirow{3}{*}{$\underset{\text { Vitamin } A}{\text { dosage }}$} & \multicolumn{6}{|c|}{ Plasma vitamin A (USP units per 100 cc.) } & \multicolumn{6}{|c|}{ Plasma carotene (mgm. per cent) } \\
\hline & & & \multicolumn{6}{|c|}{ Hours after cod liver oil taken } & \multicolumn{6}{|c|}{ Hours after cod liver oil taken } \\
\hline & & & $\mathbf{0}$ & 3 & 6 & 9 & 12 & 24 & $\mathbf{0}$ & 3 & 6 & 9 & 12 & 24 \\
\hline $\begin{array}{l}\text { Normals........ } \\
\text { Normals........ } \\
\text { Cirrhosis...... } \\
\text { Acute catarrhal } \\
\text { jaundice...... }\end{array}$ & $\begin{array}{l}4 \\
8 \\
5 \\
1\end{array}$ & $\begin{array}{c}\text { USP units } \\
20,000 \\
100,000 \\
100,000 \\
100,000\end{array}$ & $\begin{array}{r}140 \\
168 \\
44 \\
63\end{array}$ & $\begin{array}{r}190 \\
423 \\
141 \\
95\end{array}$ & $\begin{array}{l}214 \\
374 \\
111 \\
118\end{array}$ & $\begin{array}{c}165 \\
243^{*} \\
84 \\
105\end{array}$ & $\begin{array}{l}154 \\
210^{*} \\
74 \\
105\end{array}$ & $\begin{array}{r}151 \\
172 \\
47\end{array}$ & $\begin{array}{l}0.148 \\
0.110 \\
0.079 \\
0.040\end{array}$ & $\begin{array}{l}0.148 \\
0.111 \\
0.073 \\
0.040\end{array}$ & $\begin{array}{l}0.148 \\
0.109 \\
0.076 \\
0.035\end{array}$ & $\begin{array}{l}0.148 \\
0.075 \\
0.035\end{array}$ & $\begin{array}{l}0.148 \\
0.075 \\
0.035\end{array}$ & $\begin{array}{l}0.150 \\
0.108 \\
0.077 \\
0.035\end{array}$ \\
\hline
\end{tabular}

* Average of 2 cases. In subsequent curves the 9- and 12-hour determinations were omitted, since it was clear that no further rise of the plasma level occurred after 6 hours.

after 3 hours in 5 of the cases and after 6 hours in 3 cases. At the end of 24 hours the plasma levels were at or only slightly above the original fasting values. The average total increase in the plasma level of vitamin A after the ingestion of 100,000 U.S.P. units was almost four times as great as the average increase after the ingestion of 20,000 U.S.P. units of the vitamin. The administration of this large dose of vitamin $A$ in the form of a cod liver oil concentrate had no effect on the plasma levels of carotene in any of the subjects.

In the 5 cases of cirrhosis of the liver and in the 1 case of acute catarrhal jaundice the larger dose of vitamin A was given (100,000 U.S.P. units). None of the patients with cirrhosis was jaundiced, but 4 of them had ascites. In 3 of the 5 cases, the fasting levels of vitamin $A$ in the plasma were very low, i.e., 18 to 48 U.S.P. units per $100 \mathrm{cc}$. of plasma, and in the other 2 cases the fasting plasma levels were below the normal range of 88 to 188 U.S.P. units per 100 cc. of plasma, which we have previously observed (2). The ingestion of 100,000 U.S.P. units of vitamin A was followed by a rise in the plasma levels of vitamin $\mathrm{A}$ in the patients with cirrhosis, but the increase was much less than that which occurred in the normal subjects following the same dose. The peak of the increase occurred in most of the cases at the third hour and averaged 99 U.S.P. units, whereas in the normal subjects the average increase was 318 U.S.P. units per 100 cc. of plasma. In the patients with cirrhosis, as in the normals, the plasma levels of vitamin A re- turned to about the original values after 24 hours. There was no change in the plasma levels of carotene during the time of the observations. In all the patients with cirrhosis the plasma levels of carotene were lower than in the normal subjects.

In the one case of jaundice unassociated with cirrhosis of the liver, the response to the ingestion of 100,000 U.S.P. units of vitamin A was similar to that observed in the patients with cirrhosis (Table I). The total rise in the plasma level of vitamin A was 55 U.S.P. units per 100 cc. of plasma. In this patient the level of carotene was very low, $0.040 \mathrm{mgm}$. per cent, and the administration of the cod liver oil concentrate had no effect on the level of carotene.

The amount of the cod liver oil concentrate used was only $5 \mathrm{cc}$., so that it seemed unlikely that the diminished response in the plasma level of vitamin $\mathrm{A}$ in the patients with cirrhosis of the liver was due to any impairment in absorption. However, to rule this question out and to satisfy ourselves that patients with cirrhosis of the liver could be saturated with vitamin $A$, one patient with cirrhosis was fed 300,000 U.S.P. units of vitamin A daily. The plasma level before vitamin A was begun was 40 U.S.P. units per $100 \mathrm{cc}$. After 3 days the plasma level rose to 118 U.S.P. units per $100 \mathrm{cc}$. Vitamin A was continued in doses of 100,000 U.S.P. units daily for 9 weeks and then, following the test dose, the plasma levels of vitamin were determined at the usual intervals. The level of vitamin $\mathrm{A}$ in the plasma rose 220 U.S.P. units. This response, although not quite as great as the average observed in the 


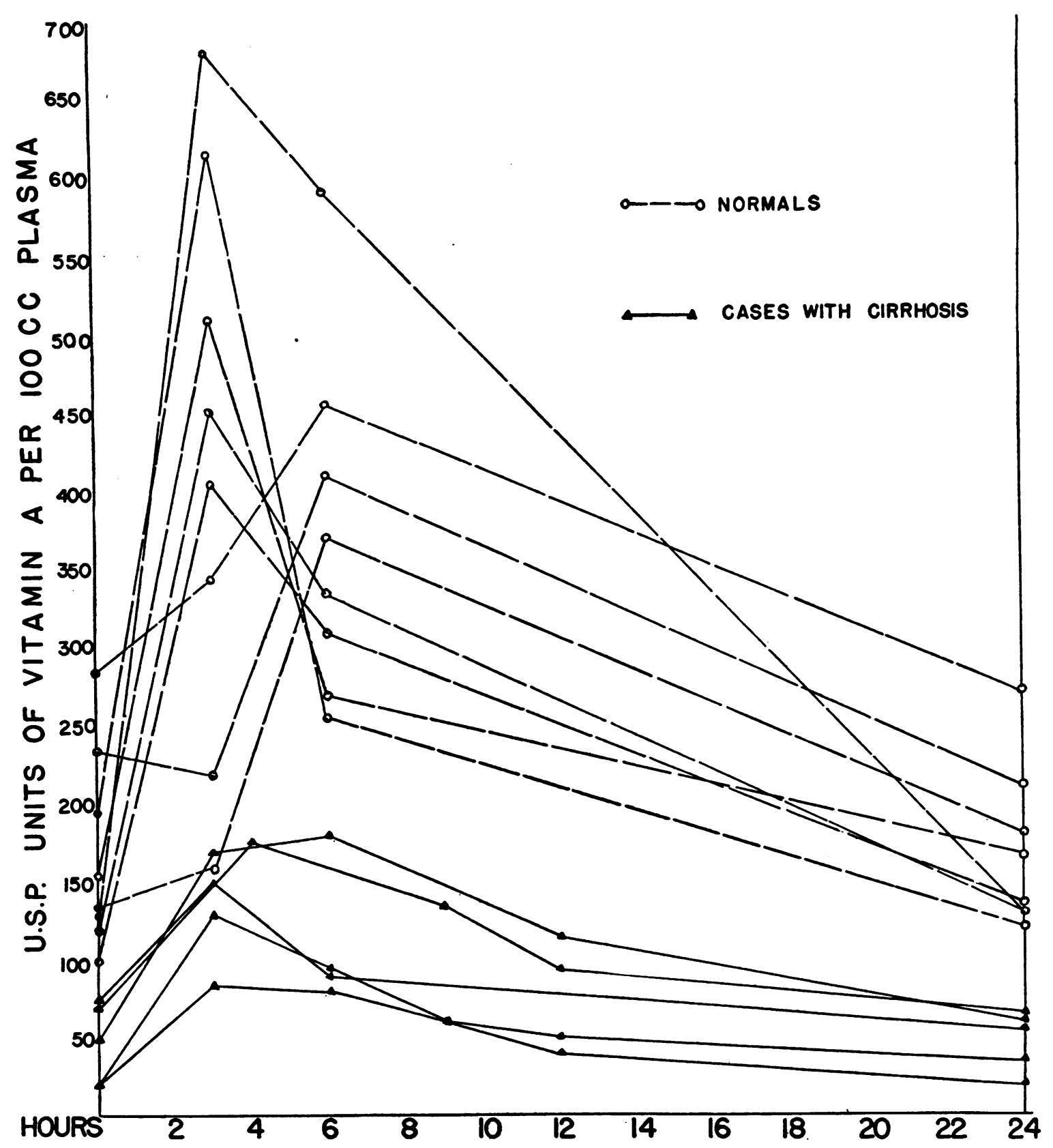

Fig. 1. The Plasma levels of Vitamin A in Normal and Cirrhotic Subjects Following the Ingestion of 100,000 U.S.P. Units of Vitamin A

normals, was more than twice as great as that observed in the 5 patients with cirrhosis and, as can be seen in the figure, was similar to the rise obtained in some of the normal subjects.

\section{DISCUSSION}

Following the administration of large doses of vitamin $A$ in the form of a cod liver oil concen- trate to human subjects, the plasma levels of vitamin A rose in' every instance. In the normal group, the extent of this rise was dependent upon the amount of vitamin A fed and, when five times the amount of vitamin A was ingested, the average increase was approximately four times as great. In all cases the plasma values returned to the original fasting levels after 24 hours. 
The administration, however, of 100,000 U.S.P. units of vitamin $A$ to patients with cirrhosis of the liver resulted in a much smaller rise in the plasma levels of the vitamin than in the normal subjects. This result was not unexpected in view of the previous observation that the concentration of vitamin $\mathrm{A}$ in the liver was decreased in patients with cirrhosis of the liver (1). Undoubtedly, a greater portion of the ingested vitamin was retained by the liver in the patients with cirrhosis than in the normal subjects. It seemed probable that certain other pathological conditions of the liver might also influence the liver stores of vitamin A. This was suggested by the fact that, in the patient with acute catarrhal jaundice, the plasma level of vitamin A was low and the response to the test dose was similar to that observed in the patients with cirrhosis.

In neither the normal subjects nor in the patients with cirrhosis of the liver were the levels of carotene in the plasma changed following the administration of the cod liver oil concentrate. There was no carotene in the concentrate and, apparently, the level of carotene in the plasma will only be altered when carotene itself is administered.

Pett and LePage have reported (5) a definite correlation between the vitamin A level in the blood and the visual test for vitamin A deficiency. Haig et al. (6) noted that, in patients with cirrhosis of the liver, there was an impairment in dark adaptation. Our findings, therefore, of a low plasma level of vitamin A in patients with cirrhosis of the liver would fit in with the observations of Haig, Hecht and Patek and would corroborate the observations of Pett and LePage that there is a correlation between the vitamin A level in the blood and the visual recovery time. In later work Patek and Haig (7) reported that dark adaptation was improved in patients with cirrhosis of the liver following the feeding of vitamin $A$ in the form of cod liver oil. This also fits in with the results that we obtained in the one patient with cirrhosis of the liver who, following the daily ingestion of cod liver oil, had a normal plasma level of vitamin A and a normal response to a standard dose of the vitamin.

The results obtained in these studies suggest that there is a deficiency of vitamin $A$ in patients with cirrhosis of the liver which is reflected in the low plasma level of vitamin A. This deficiency may be partly due to the liver damage and it may also be due to the fact that vitamin $A$ is normally ingested in the form of its precursor carotene which, in the presence of liver damage, may not be converted to vitamin $A$.

The administration of standard doses of vitamin A to normal subjects and to patients with cirrhosis of the liver-serves as a "tolerance test." This procedure might well be used as a measure of vitamin A deficiency in patients with cirrhosis of the liver or in patients with liver damage.

\section{SUMMARY}

Standard doses of cod liver oil in the form of a cod liver oil concentrate were given to 12 normal subjects, to 5 patients with cirrhosis of the liver and to 1 case with acute catarrhal jaundice. Four of the normal subjects received a dose of 20,000 U.S.P. units of vitamin A and 8 received a dose five times as great $(100,000$ U.S.P. units of vitamin A). The larger dose resulted in a greater increase in the plasma levels of vitamin A determined at intervals over a 24-hour period.

The patients with cirrhosis of the liver and the patient with jaundice were given 100,000 U.S.P. units of vitamin $A$. The rise in the plasma level of vitamin $\mathrm{A}$, compared to the rise which occurred in the plasma levels in the normal subjects, was much less in the patients with liver damage.

The results suggest that a test of this type may serve as an index of the degree of vitamin A deficiency in patients with cirrhosis of the liver or with other diseases of the liver.

The findings of a low plasma level of vitamin $A$ in patients with cirrhosis of the liver fit in with the previous observations of a lowered concentration of vitamin $A$ in the livers of such patients.

\section{BIBLIOGRAPHY}

1. Ralli, E. P., Papper, E., Paley, K., and Bauman, E., The vitamin $A$ and carotene content of normal and pathological human livers. Arch. Int. Med., 1941, 68, 102. 
2. Ralli, E. P., Bauman, E., and Roberts, L. (In press.)

3. Kimble, M. S., The photoelectric determination of vitamin A and carotene in human plasma. J. Lab. and Clin. Med., 1939, 24, 1055.

4. Stueck, G. H., Flaum, G., and Ralli, E. P., The serum carotene in diabetic patients. J. A. M. A., 1937, 109, 343.

5. Pett, L. B., and LePage, G. A., Vitamin A deficiency.
III. Blood analysis correlated with a visual test. J. Biol. Chem., 1940, 132, 585.

6. Haig, C., Hecht, S., and Patek, A. J., Vitamin A and rod-cone dark adaptation in cirrhosis of the liver. Science, 1938, 87, 534.

7. Patek, A. J.2 and Haig, C., The occurrence of abnormal dark adaptation and its relation to vitamin A metabolism in patients with cirrhosis of the liver. J. Clin. Invest., 1939, 18, 609. 